\title{
LIDAR-DERIVED PARTICLE CONCENTRATIONS IN PLUMES FROM ARCTIC LEADS
}

\author{
by \\ Edgar L Andreas \\ (U.S. Army Cold Regions Research and Engineering Laboratory, 72 Lyme Road, Hanover, \\ NH $03755-1290$, U.S.A.) \\ and \\ Martin W. Miles, Roger G. Barry and Russell C. Schnell \\ (Cooperative Institute for Research in Environmental Sciences, University of Colorado, Boulder, CO \\ 80309-0499, U.S.A.)
}

\section{ABSTRACT}

With an airborne lidar, we have observed massive plumes of condensate particles rising from wintertime leads in the Arctic Ocean. Some of these plumes reached an altitude of $4 \mathrm{~km}$; some extended over $200 \mathrm{~km}$ down-wind from their surface source. Here we invert the lidar equation and use lidar backscatter data to infer particle concentrations within two such plumes. Assuming that the plumes consist of supercooled water droplets of radius $5 \mu \mathrm{m}$, we estimate typical concentrations of $3-6 \times 10^{5}$ droplets $\mathrm{m}^{-3}$ just above the leads. Concentrations within the plumes can still be as high as $10^{4}$ droplets $\mathrm{m}^{-3}$ at an altitude of $3 \mathrm{~km}$ and $200 \mathrm{~km}$ down-wind from some leads. Had we assumed that the plume particles are ice spheres of radius $40 \mu \mathrm{m}$, concentrations would be just 100 times less than these.

\section{PLUMES FROM LEADS}

Leads and polynyas are regions of open water or thin, newly formed ice that occur in the pack ice of the Arctic Ocean in response to wind and currents. They are climatologically important because in winter heat passes through leads from the relatively warm ocean to the cold atmosphere two orders of magnitude faster than it does through the ubiquitous ice (Badgley, 1966; Maykut, 1978; Andreas and others, 1979).

Several experiments over narrow leads and polynyas (Badgley, 1966; Andreas and others, 1979, 1981; Smith and others, 1983) did not dispel the notion that the heat and moisture lost from open water in winter remains within the atmospheric boundary layer, trapped by the prevalent Arctic inversion. But we have recently documented high-rising plumes of water droplets or ice crystals that clearly originated from major leads north of Ellesmere Island (Schnell and others, 1989). Some of these plumes reached an altitude of $4 \mathrm{~km}$, while others extended down-wind from their surface source over $200 \mathrm{~km}$. They were massive. Such leads and their associated plumes may produce basin-wide climatological effects.

To continue toward our ultimate goal of understanding how much lead-derived heat and moisture reaches an arbitrary level in the atmosphere, we here estimate particle concentrations in two of these massive plumes. The plumes were observed with an airborne, downward-looking, $1.06 \mu \mathrm{m}$ lidar; we convert the Rayleigh (backscatter) ratio measured by the lidar into plots of particle concentrations within the plumes.

\section{THE LIDAR EQUATION}

A lidar experiencing backscattering obeys (Collis and Russell, 1976)

$$
P_{\mathrm{r}}(R)=G P_{0}(c \tau / 2) B_{\pi}(R) A R^{-2} \exp \left[-2 \int_{0}^{R} \propto\left(R^{\prime}\right) \mathrm{d} R^{\prime}\right] .
$$

Here, $P_{\mathrm{r}}$ is the instantaneous received power; $P_{0}$, the transmitted power; $R$, the range to the scatterer; $G$, a calibration constant; $c$, the speed of light; $\tau$, the lidar pulse duration; $R^{\prime}$, position along the propagation path; $\beta \pi$ and $\alpha$, respectively, the volume backscattering coefficient and the volume extinction coefficient of the atmosphere; and $A$, the receiver area.

The extinction $\alpha$ results from two effects, molecular scattering and absorption $\left(\alpha_{\mathrm{m}}\right)$ and aerosol scattering and absorption $\left(\alpha_{\mathrm{a}}\right)$ (Collis and Russell, 1976); thus

$$
\alpha=\alpha_{m}+\alpha_{a} .
$$

The backscattering coefficient, likewise, is the sum of molecular $\left(\beta_{\pi \mathrm{m}}\right)$ and aerosol $\left(\beta_{\pi \mathrm{a}}\right)$ backscattering,

$$
\beta_{\pi}=\beta_{\pi \mathrm{m}}+\beta_{\pi \mathrm{a}} .
$$

From the lidar observations, we computed the so-called Rayleigh ratio $\mathrm{B}$, the ratio backscattered power from an aerosol cloud to backscattered power from clear air, where this clear-air backscatter value came from flight segments through clear air. From Equations $(1)-(3)$, the Rayleigh ratio is

$$
B(R)=\frac{\left[\beta_{\pi \mathrm{m}}(R)+\beta_{\pi \mathrm{a}}(R)\right] \exp \left[-2 \int_{0}^{R} \alpha_{\mathrm{a}}\left(R^{\prime}\right) \mathrm{d} R^{\prime}\right]}{\beta_{\pi \mathrm{m}}(R)}
$$

Because the aerosol backscattering coefficient depends on the number of aerosol particles present through

$$
\beta_{\pi \mathrm{a}}(R, \lambda)=\int_{0}^{\infty} \sigma_{\pi}(a, \lambda, m) C(a, R) \mathrm{d} a
$$


where $\lambda$ is the lidar wavelength, $\sigma_{\pi}$ is the backscattering cross-section, and $C$ is the number concentration of particles with radius $a$ and complex refractive index $m$, we have a means of estimating particle concentrations from the Rayleigh ratio.

A few simplifying assumptions are, however, necessary. Andreas and others (1981) concluded that the vapour escaping from wintertime leads condensed into droplets having a fairly narrow size distribution with a mode radius of about $5 \mu \mathrm{m}$. Such small droplets can persist supercooled even at Arctic temperatures (Schaefer, 1962; Andreas and others, 1981; Heymsfield and Sabin, 1989). Sampling at higher altitudes, Ohtake and others (1982) found that the particles over Arctic leads were ice crystals with a mode radius more like $40 \mu \mathrm{m}$. But because they were unable to sample particles with radii smaller than $10 \mu \mathrm{m}, 40 \mu \mathrm{m}$ is probably an upper limit for the mode radius of these crystals. For our calculations, we henceforth assume that a lead plume is a mono-dispersive aerosol consisting either of supercooled, spherical water droplets of radius $5 \mu \mathrm{m}$, or spherical ice crystals of radius $40 \mu \mathrm{m}$.

The backscattering cross-section in Equation (5) is usually expressed in terms of a dimensionless backscattering efficiency factor $Q_{\pi}(x, m)$,

$$
\sigma_{\pi}(a, \lambda, m)=\pi a^{2} Q_{\pi}(x, m)
$$

where $x=2 \pi a / \lambda$ is a size parameter. Because we assume that the plume consists of particles of a single size, Equation (5) thus becomes

$$
\beta_{\pi \mathrm{a}}(R, \lambda)=\pi a^{2} Q_{\pi}(x, m) C(a, R) .
$$

We computed $Q_{\pi}$ using the Mie theory computer program given by Bohren and Huffman (1983: 477-82), with values for the refractive index of water (Irvine and Pollack, 1968) and of ice (Warren, 1984) at $1.06 \mu \mathrm{m}$. For $5 \mu \mathrm{m}$ water droplets, $x=30$ and $Q_{\pi}=0.23$; for $40 \mu \mathrm{m}$ ice spheres, $x=$ 240 and $Q_{\pi}=0.36$

The aerosol extinction coefficient, $\alpha_{a}$, in Equation (4) is also related to a cross-section, the extinction cross-section $\sigma_{\mathrm{ex}}(a, \lambda, m)$, as in Equation (5). And this cross-section, in turn, is usually expressed in terms of the extinction efficiency factor $Q_{\mathrm{ex}}(x, m)$, in analogy with Equation (6). Thus, for a monodispersive aerosol, $\alpha_{\mathrm{a}}$ can be modeled as $\beta_{\pi \mathrm{a}}$ in Equation (7), $\alpha_{\mathrm{a}}(R, \lambda)=\pi a^{2} Q_{\mathrm{ex}}(x, m) C(a, R)$, where from our Mie calculations $Q_{\mathrm{ex}} \simeq 2$. From McClatchey and others (1972), we estimate that $\alpha_{9}$ is in the range $6 \times 10^{-5}$ to $2.6 \times 10^{-4} \mathrm{~m}^{-1}$. from Collis and Russell (1976), $1-5 \times 10^{-4} \mathrm{~m}^{-1}$. For the droplet concentrations that Andreas and others (1981) measured over leads, we estimate that $\alpha_{\mathrm{a}}$ is roughly $1.9 \times 10^{-4} \mathrm{~m}^{-1}$; from the conditions observed by Ohtake and others (1982), we estimate $2.0 \times 10^{-4} \mathrm{~m}^{-1}$. Because of the limited range in these estimates, for our subsequent calculations we assume that $\alpha_{\mathrm{a}}=2.0 \times 10^{-4} \mathrm{~m}^{-1}$.

Finally, we can compute the molecular backscattering coefficient, $\beta_{\pi \mathrm{m}}$, in Equation (4) from a relation given by Penndorf (1957) and McCartney (1976),

$\beta_{\mathrm{m}}(\theta)=\frac{2 \pi^{2}\left(n^{2}-1\right)^{2}}{3 N \lambda^{4}}\left[\frac{6+3 p_{\mathrm{n}}}{6-7 p_{\mathrm{n}}}\right]\left[0.7629\left(1+0.9324 \cos ^{2} \theta\right)\right]$.

Here $\beta_{m}(\theta)$ is the molecular scattering coefficient at angle $\theta, N$ is the number density of air molecules, and $p_{\mathrm{n}}(=0.035)$ is the depolarization factor. For backscatter, $\theta=180^{\circ} ;$ thus, $\beta_{\pi \mathrm{m}} \equiv \beta_{\mathrm{m}}\left(180^{\circ}\right) . \quad N$ derives simply from $N=\rho N_{\mathrm{a}} / M_{\mathrm{a}}$, where $\rho$ is the air density, $N_{\mathrm{a}}$ is Avogadro's number, and $M_{\mathrm{a}}$ is the molecular weight of air. For $n$, the real part of the refractive index of air, we use Owens' (1967) relation.

With Equation (7), with the relation for molecular backscatter $\beta_{m m}$ (Equation (8)), and with the other simplifications that we have been discussing, we can derive from Equation (4) a prediction equation for the particle concentration within lead plumes,

$$
C(a, R)=\frac{{ }^{B} \pi \mathrm{m}(R)}{\pi a^{2} Q_{\pi}(x, m)}\left[\frac{B(R)}{\exp \left(-2 \alpha_{\mathrm{a}} \Delta R\right)}-1\right]
$$

where $\Delta R$ is the range increment for which the lidar beam was within the plume.

Because the $B(R)$ term within the square brackets in Equation (9) is generally much larger than $1, C$ is almost directly proportional to $B$ and inversely proportional to $\exp \left(\alpha_{\mathrm{a}}\right)$, to $\exp (\Delta R)$, and to $Q_{\pi}$. Our Mie computations showed that $Q_{\pi}$ is very sensitive to particle size; uncertainty in the particle radius, therefore, probably introduces a factor-of-five uncertainty in our concentration estimates through the $a^{2}$ and $Q_{\pi}$ terms in Equation (9).

\section{PARTICLE CONCENTRATIONS IN THE PLUMES}

We here consider the lidar data collected on 27 January 1984 during the Arctic Gas and Aerosol Sampling Program (AGASP) (Schnell, 1984). Figure 1 shows the flight track north from Thule, over Alert, and then out over the frozen Arctic Ocean (Kent and others, 1986). Nominal flight altitude was $5800 \mathrm{~m}$. In the figure we also show major leads visible in Defense Meteorological Satellite Program (DMSP) infrared images from the time of the flight. At least two of these leads, as marked in the figure, were open and produced major plumes that we have documented elsewhere (Schnell and others, 1989). We derive particle concentrations in these two plumes.

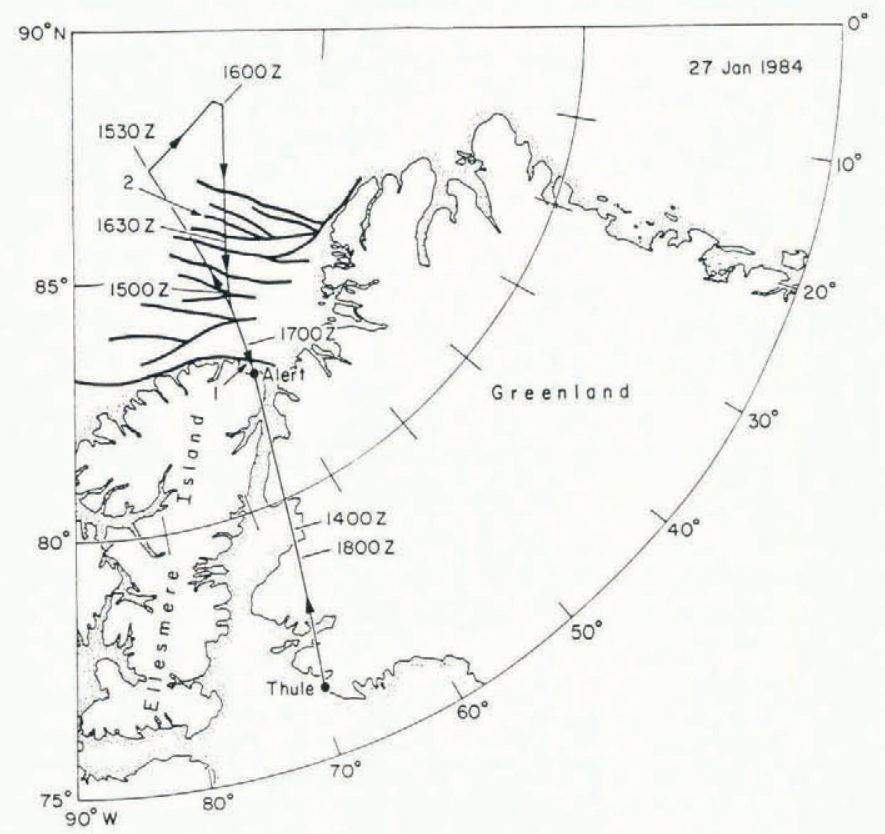

Fig. 1. Flight track out of Thule, Greenland, on 27 January 1984. Major leads along the flight track that are visible in DMSP images are indicated. The two plumes discussed in this paper originated in the leads marked 1 (Fig. 2) and 2 (Fig. 3) in the figure.

The flaw lead north of Ellesmere Island produced an enormous plume that reached an altitude of $3 \mathrm{~km}$ and extended down-wind (northward) over $200 \mathrm{~km}$ (Fig. 2). Although we do not have information on the width of this lead, the surface droplet concentrations in Figure 2 and near-concurrent satellite imagery suggest that it may have been at least $20 \mathrm{~km}$ wide.

The second plume (Fig. 3) originated in a lead at about $85^{\circ} \mathrm{N}$, well into the interior of the Arctic ice pack. This plume reached an altitude of almost $4 \mathrm{~km}$. Although again we have no direct observations of the width of this lead, given the meteorological conditions measured by the 


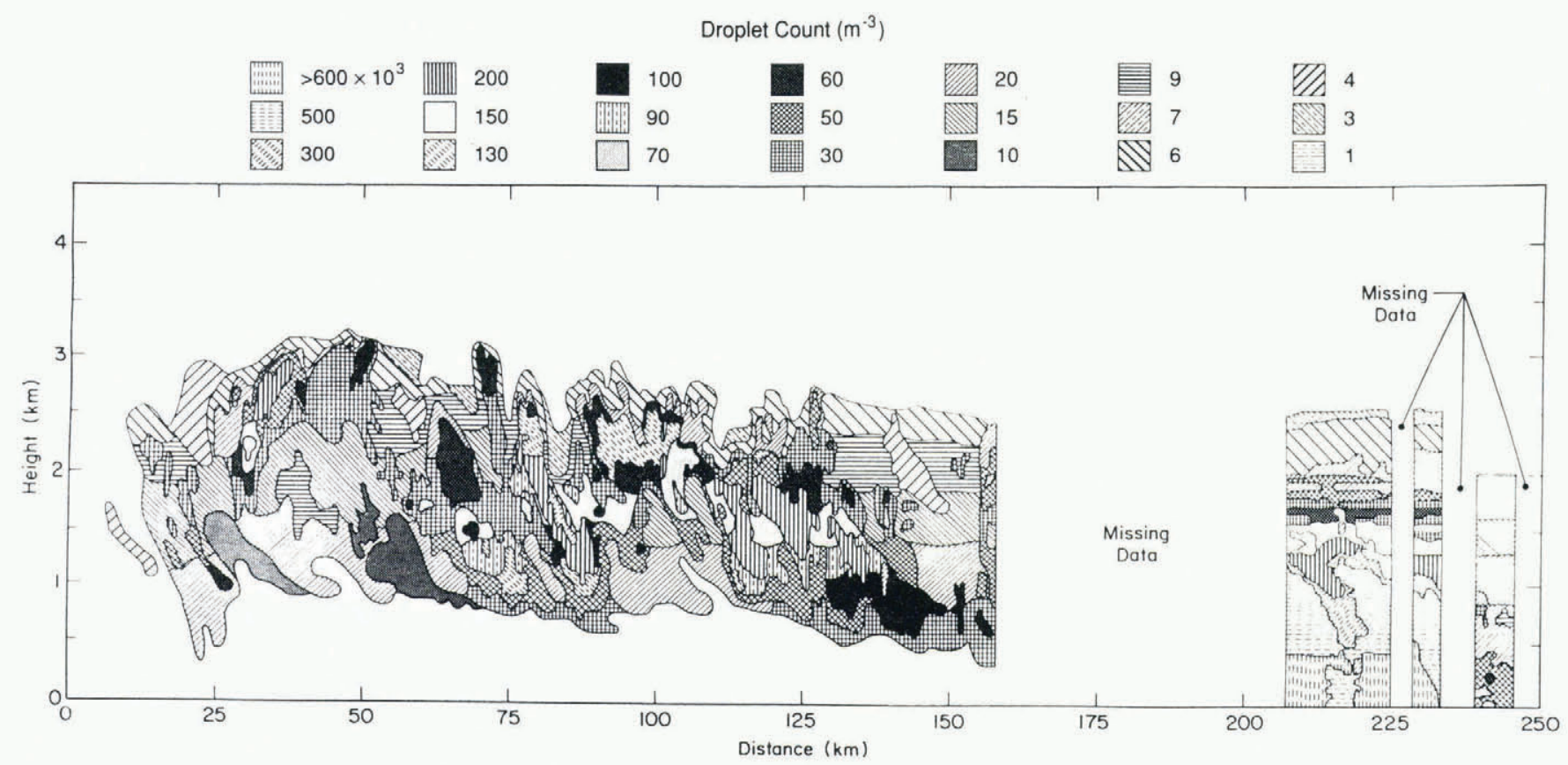

Fig. 2. Concentrations of $5 \mu \mathrm{m}$ water droplets computed for the plume observed between 16.35 and $17.05 \mathrm{Z}$ that originated in the flaw lead north of Ellesmere Island. If the plume particles were $40 \mu \mathrm{m}$ ice spheres, instead of water droplets, concentrations would be just 100 times less. The origin of the abscissa is arbitrarily located.

$12.00 \mathrm{Z}$ Alert radiosounding on 27 January, we estimated that a lead would have to be roughly $10 \mathrm{~km}$ wide to provide the thermal energy necessary for a plume to reach $4 \mathrm{~km}$ (Schnell and others, 1989). Satellite imagery and the maximum in calculated surface droplet concentration shown in Figure 3 corroborate that the lead was roughly $10 \mathrm{~km}$ wide.

Figures 2 and 3 show the concentrations of droplets with radius $5 \mu \mathrm{m}$. For ice crystals with radius $40 \mu \mathrm{m}$, the concentrations are just 100 times less. The figures generally give droplet concentrations to only one significant figure to indicate the uncertainty in our calculations. In taking $\alpha_{a}$ to be a constant of $2 \times 10^{-4} \mathrm{~m}^{-1}$, in effect, we are assuming that plumes of $5 \mu \mathrm{m}$ droplets have a uniform concentration of $130 \times 10^{4}$ droplets $\mathrm{m}^{-3}$ or plumes of $40 \mu \mathrm{m}$ ice spheres have a concentration of $2 \times 10^{4}$ crystals $\mathrm{m}^{-3}$. Consequently, Equation (9) overestimates the particle concentration in regions for which the overlying plume has concentrations

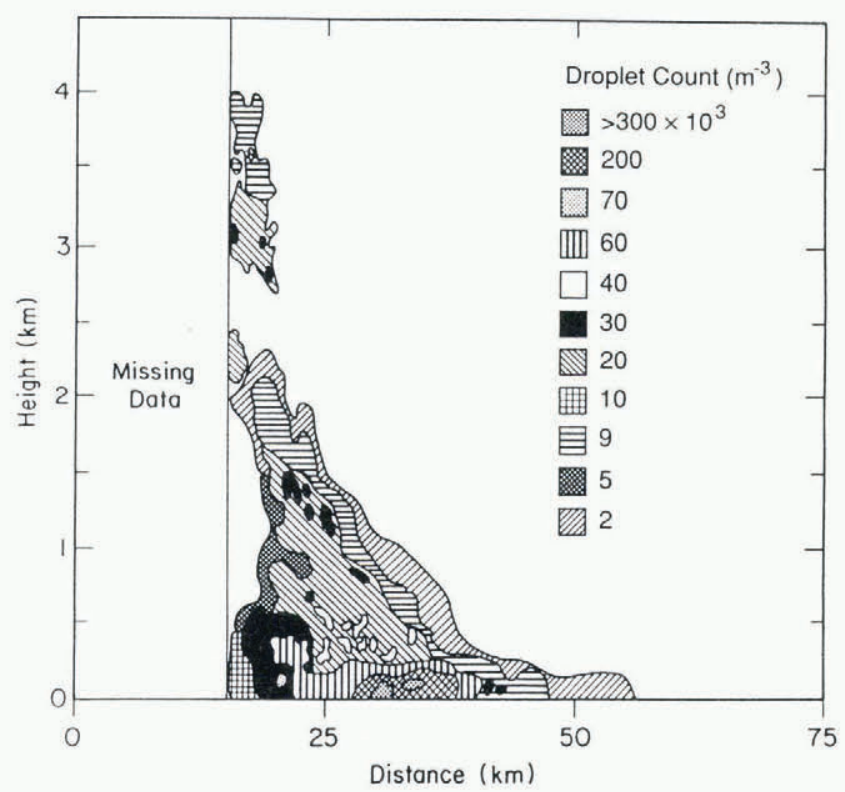

Fig. 3. As in Figure 2, except this is the plume observed between 16.25 and $16.30 \mathrm{Z}$. greater than $130 \times 10^{4}$ droplets $\mathrm{m}^{3}$ (or $2 \times 10^{4}$ crystals $\mathrm{m}^{-3}$ ), which is everywhere within both plumes. Therefore, considering the uncertainties discussed earlier, we feel that the concentrations in Figures 2 and 3 are accurate to within an order of magnitude.

The $5 \mu \mathrm{m}$ droplet concentrations are somewhat smaller than those observed by Andreas and others (1981) within a meter of the surface of narrow leads. They found maximum condensate concentrations of $1-20 \times 10^{7}$ droplets $\mathrm{m}^{-3}$. But because the lidar has a vertical resolution of about $30 \mathrm{~m}$, it cannot measure as near the surface as Andreas and others did; as a result, it yields maximum concentrations somewhat less than they found.

Except in the immediate vicinity of their source, these plumes have particle concentrations lower than those measured in most clouds (Carrier and others, 1967). The bulk of a plume is therefore not visible. In fact, plume particle concentrations are typical of subvisible cirrus clouds (Braham and Spyers-Duran, 1967; Hoff, 1988; Sassen and others, 1989). In light of the computed concentrations, knowing that the ambient air temperature was near $-30^{\circ} \mathrm{C}$ in the lower $4 \mathrm{~km}$, and realizing that the relative humidity needs to be only about $75 \%$ for air to be saturated with respect to ice at $-30^{\circ} \mathrm{C}$, we conclude that the bulk of the observed plumes consist of ice crystals.

The $12.00 \mathrm{Z}$ Alert radiosounding on 27 January showed a main inversion at $600-700 \mathrm{~m}$ and an overall drop in potential temperature of $25^{\circ} \mathrm{C}$ between the surface and $1500 \mathrm{~m}$. Yet such atmospheric stability was clearly unable to constrain the plumes near the surface. With lead-derived heat and moisture, thus, capable of reaching the midtroposphere, wide leads have the potential to influence the climate not just locally but basin-wide.

Though invisible, the plumes may also affect the climate radiatively. Assuming ice crystal concentrations of $1-100 \times 10^{4} \mathrm{~m}^{-3}$, Curry and others (1989) computed inf rared radiative cooling rates in the Arctic atmosphere that were about $2{ }^{\circ} \mathrm{C} \mathrm{d}^{-1}$ greater than for clear air. This atmospheric radiation loss would, in turn, warm the sea-ice surface and have significant influence on the surface energy budget. The plumes shown in Figures 2 and 3 both have particle concentrations similar to those used in the calcula- tions by Curry and others. Thus, the Ellesmere Island flaw lead (Fig. 2) has, in effect, thrown a warming blanket of condensate particles over the sea ice for more than $200 \mathrm{~km}$ down-wind. Similar leads that occur in the marginal seas north of Siberia probably produce like effects in that area. 


\section{ACKNOWLEDGEMENTS}

We would like to thank G. Koh, J.A. Curry, K.C. Jezek, S.G. Warren, and an anonymous reviewer for comments on the manuscript. Discussions with A.W. Hogan were very helpful. L.F. Radke, C.A. Brock, M.P. McCormick, and J.L. Moore provided technical help with the data collection and processing. The U.S. Office of Naval Research supported this work with contracts N0001486K0695, N0001488WM22012, and N0001489WM22006.

\section{REFERENCES}

Andreas, E.L., C.A. Paulson, R.M. Williams, R.W. Lindsay, and J.A. Businger. 1979. The turbulent heat flux from Arctic leads. Boundary-Layer Meteorol., 17(1), 57-91.

Andreas, E.L., R.M. Williams, and C.A. Paulson. 1981 Observations of condensate profiles over Arctic leads with a hot-film anemometer. $Q$. J. R. Meteorol. Soc., 107(452), 437-460.

Badgley, F.I. 1966. Heat budget at the surface of the Arctic Ocean. In Fletcher, J.O., ed. Proceedings of the Symposium on the Arctic Heat Budget and Atmospheric Circulation. Santa Monica, CA, Rand Corporation, 267-277. (Memo. RM-5233-NSF.)

Bohren, C.F. and D.R. Huffman. 1983. Absorption and scattering of light by small particles. New York, Wiley-Interscience.

Braham, R.R., Jr. and P. Spyers-Duran. 1967. Survival of cirrus crystals in clear air. J. Appl. Meteorol., 6(6), 1053-1061.

Carrier, L.W., G.A. Cato, and K.J. von Essen. 1967. The backscattering and extinction of visible and infrared radiation by selected major cloud models. Appl. Opt., 6(7), 1209-1216.

Collis, R.T.H. and P.B. Russell. 1976. Lidar measurements of particles and gases by elastic backscattering and differential absorption. In Hinkley, E.D., ed. Laser monitoring of the atmosphere. Berlin, Springer-Verlag, $71-151$.

Curry, J.A., L.F. Radke, C.A. Brock, and E.E. Ebert. 1989. Arctic ice-crystal haze. In Symposium on the Role of Clouds in Atmospheric Chemistry and Global Climate, 29 January - 3 February 1989, Anaheim, Calif. Preprint Volume. Boston, American Meteorological Society, 114-117.

Heymsfield, A.J. and R.M. Sabin. 1989. Cirrus crystal nucleation by homogeneous freezing of solution droplets. J. Atmos. Sci., 46(14), 2252-2264.

Hoff, R.M. 1988. Vertical structure of Arctic haze observed by lidar. J. Appl. Meteorol., 27(2), 125-139.

Irvine, W.M. and J.B. Pollack, 1968. Infrared optical properties of water and ice spheres. Icarus, 8(2), 324-360.

Kent, G.S., L.R. Poole, and M.P. McCormick. 1986 Characteristics of Arctic polar stratospheric clouds as measured by airborne lidar. J. Atmos. Sci., 43(20), 2149-2161.

McCartney, E.J. 1976. Optics of the atmosphere: scattering by molecules and particles. New York, John Wiley.

McClatchey, R.A., R.W. Fenn, J.E.A. Selby, F.E. Volz, and J.S. Garing. 1972. Optical properties of the atmosphere. Third edition. Bedford, MA, Air Force Cambridge Research Laboratories. (AFCRL-72-0497.)

Maykut, G.A. 1978. Energy exchange over young sea ice in the central Arctic. J. Geophys. Res., 83(C7), 3646-3658.

Ohtake, T., K. Jayaweera, and K. Sakurai. 1982. Observation of ice crystal formation in lower Arctic atmosphere. J. Atmos. Sci., 39(12), 2898-2904.

Owens, J.C. 1967. Optical refractive index of air: dependence on pressure, temperature and composition. Appl. Opt., 6(1), 51-59.

Penndorf, R. 1957. Tables of the refractive index for standard air and the Rayleigh scattering coefficient for the spectral region between 0.2 and $20.0 \mu$ and their application to atmospheric optics. J. Opt. Soc. Am., 47(2), $176-182$.

Sassen, K., M.K. Griffin, and G.C. Dodd. 1989. Optical scattering and microphysical properties of subvisual cirrus clouds, and climatic implications. J. Appl. Meteorol., 28(2), 91-98.

Schaefer, V.J. 1962. Condensed water in the free atmosphere in air colder than $-40^{\circ} \mathrm{C}$. J. Appl. Meteorol., 1(4), 481-488.

Schnell, R.C. 1984. Arctic haze and the Arctic Gas and Aerosol Sampling Program (AGASP). Geophys. Res. Lett. 11(5), 361-364.

Schnell, R.C., and 7 others. 1989. Lidar detection of leads in Arctic sea ice. Nature, 339(6225), 530-532.

Smith, S.D., R.J. Anderson, G. den Hartog, D.R. Topham, and R.G. Perkin. 1983. An investigation of a polynya in the Canadian Archipelago. 2. Structure of turbulence and sensible heat flux. J. Geophys. Res., 88(C5), 2900-2910.

Warren, S.G. 1984. Optical constants of ice from the ultraviolet to the microwave. Appl. Opt., 23(8), $1206-1225$. 